\title{
Identification on Mantle Cell Lymphoma Using CD20 and CD5 Coupled Upconversion Fluorescent Nanoprobes
}

\author{
Mingkai Zhang, ${ }^{1}$ Yang Gao, ${ }^{2}$ Jialiang Wang, ${ }^{3}$ Zhanbo Liu, ${ }^{2}$ Zaishun Jin, ${ }^{2}$ Jianbo Yu, ${ }^{2}$ \\ Yukuan Feng, ${ }^{2}$ and Qiang Lü ${ }^{2}$ \\ ${ }^{1}$ Jiangxi Medical College, Nanchang University, Jiangxi 330031, China \\ ${ }^{2}$ Heilongjiang Provincial Key Laboratory of Cancer Prevention and Treatment, Mudanjiang Medical University, \\ Heilongjiang 157011, China \\ ${ }^{3}$ Division of Medicament, Mudanjiang Hongqi Hospital, Heilongjiang 157011, China
}

Correspondence should be addressed to Qiang Lü; qianglue@126.com

Received 11 January 2018; Accepted 25 March 2018; Published 2 May 2018

Academic Editor: Paulo Cesar Morais

Copyright ( $\odot 2018$ Mingkai Zhang et al. This is an open access article distributed under the Creative Commons Attribution License, which permits unrestricted use, distribution, and reproduction in any medium, provided the original work is properly cited.

In order to determine a particular tumor cell via nanomaterials, we introduce the preparation of CD20 and CD5 coupled nanoprobes (denoted as CD20 and CD5 nanoprobes for convenience) and an application in identification of mantle cell lymphoma (MCL) from B-cell lymphoma. In this work, CD20 and CD5 nanoprobes were prepared by selectively oxidizing the carbon-carbon double bonds of oleate ligands on the surfaces of $\mathrm{NaYF}_{4}: \mathrm{Yb}^{3+}, \mathrm{Tm}^{3+}$ and $\mathrm{NaYF}_{4}: \mathrm{Yb}^{3+}, \mathrm{Er}^{3+}$ nanoparticles and, respectively, coupling carboxyl groups on the particles' surfaces with CD20 and CD5 monoclonal antibodies through EDC/NHS crosslinking agents. After in situ hybridized Jeko-1 cells and Raji cells as a reference with CD20 and CD5 nanoprobes, in vitro double-color upconversion fluorescence imaging of Jeko-1 cells was demonstrated through visualization of blue and green fluorescence under a $980 \mathrm{~nm}$ laser excitation. Moreover, in vivo upconversion fluorescence imaging of the transplanted cancer model was also measured. These experimental results indicate that Jeko-1 cells have been specifically labeled by CD20 and CD5 nanoprobes. It is therefore concluded that CD20 and CD5 nanoprobes could be used to specially differentiate mantle cell lymphoma (MCL) from B-cell lymphoma.

\section{Introduction}

In optical biomedical imaging, dye markers such as hematoxylin-eosin staining (HE stain) are usually utilized as exogenous contrast agents to highlight the focuses and provide more detailed information on pathology and pathogeny of disease $[1,2]$. When using these dyes, optical imaging only fulfills conventional biomedical research and clinical diagnosis because these dyes do not specifically distinguish pathological tissues. Fortunately, photoluminescence imaging, with the aid of organic fluorophores typified by rhodamine and cyanine dye, can make up the insufficiency of optical imaging $[3,4]$. These organic fluorophores help to identify the natures of cells in medical research and clinical diagnostics/therapeutics. Unfortunately, these organic fluorophores have suffered some shortcomings [5-7]: (i) smaller spectral shifts between emission and excitation light could increase excitation-light-induced background and reduce signal-noise ratio of photoluminescence imaging. (ii) Photobleaching of organic fluorophores at high illumination intensity limits bioapplications of photoluminescence imaging in early detection, screening, and image-guided therapy of life-threatening diseases.

In order to overcome the photobleaching of organic fluorophores, novel inorganic fluorescence semiconductor quantum dots (QDots) obtain rapid development since 1998 [8]. The QDots display several spectral features. One is that the emission spectra of homogeneous sized QDots are about twofold narrower than those of typical cyanine dye; another is that the QDots absorption wavelengths are much shorter and broader than organic fluorophores, allowing excitation with a spectrally wide light source [9]. 
Finally, the QDots have more photostability against photobleaching than organic fluorophores [10], which indicates that it is possible for the QDots to label internal cellular structures. Thus, the QDots conjugated to biomolecules via antigen-antibody biochemical reactions can serve as photoluminescence biolabels. However, there has been a serious safety problem in substituting the QDots for organic fluorophores in the bioimaging and clinical diagnosis of living samples because toxicity of cadmium and excitation at short wavelengths can cause serious damage to living cells.

Based on anti-Stokes-shifted photoluminescence, another novel inorganic fluorophore is lanthanide-doped upconversion nanoparticles, which are capable of converting longer wavelength radiation into shorter wavelength fluorescence via a stepwise photon governance mechanism in the intra- $4 \mathrm{f}^{n}$ energy levels of lanthanide ions [11-13]. Hence, a safe excitation mode is the most unusual advantages of lanthanide-doped nanoparticles for bioimaging application. It is well known that infrared radiation with a wavelength of 700-1000 nm, which is the "optical window" of biological tissues $[14,15]$, can penetrate biological tissues up to several inches without causing much light scattering and photodamage to the tissues due to a nearly infrared transparence of biological tissues [16, 17]. Inorganic lanthanide-doped nanoparticles have also demonstrated high photostability and low toxicity [18]. Compared with organic fluorophores and the QDots, these features of upconversion nanoparticles make them more suitable as fluorescence biolabels for in vitro and in vivo optical imaging applications. Recently, some research teams such as Zhang et al. [19-21], Wang et al. [22, 23], Li et al. [17, 24, 25], Yan et al. [26, 27], Prasad et al. [28, 29], Dai et al. [30, 31], and Liu et al. [32, 33] have reported the developments in in vitro and in vivo bioimaging using upconversion-based nanoprobes. For the most bioimaging researches above, they often chose Hela, ovarian carcinoma (OVCAR3), colonic adenocarcinoma (HT29), human pancreatic cancer (Panc 1), and nasopharyngeal epidermal carcinoma $(\mathrm{KB})$ cells as the targeted cells, utilized singlecolored upconversion nanoprobes to conjugate to these tumor cells because these anchorage-dependent tumor cells are convenient for attachment culture, hybridization with nanoprobes in situ, and fluorescent imaging. Their experimental results showed that these upconversion-based nanoprobes could be used as fluorescent labels of tumors in bioimaging applications. Moreover, it is impressive that upconversion nanoparticles can be also applied to the detection of trace organic dyes such as Rhodamine B and sodium fluorescein in living organisms based on a LRET process [34-36], as well as latent fingerprint development in forensic sciences [37, 38].

It is well known that there are different tumor antigens on/inside tumor cells, where some antigens are specific; others are nonspecific. These specific antigens can be used as molecular markers for biomedical diagnosis and treatment. Depending on one specific molecular marker, however, a physician does not differentiate and/or diagnose a tumor, much less treat and cure the tumor. Thus, it is necessary to choose the multiple specific molecular markers in order to improve the clinical diagnostic accuracy of tumors.
It is reported that MCL is a rare subtype of B-cell nonHodgkin lymphoma (NHL), accompanied by high invasiveness, bad prognosis, and hard to cure in clinical medicine [39]. It is also difficult to diagnose MCL due to its rareness. In immunophenotyping, over $90 \% \mathrm{MCL}$ is cyclin D1 overexpression $[39,40]$, being the most specific molecular marker. However, cyclin D1 is translocated into the cytoplasm and the nucleolus [39], needing transmembrane proteins as vectors to transport upconversion-based nanoprobes without permeability into living cells. Considering higher positive expression of $\mathrm{CD} 19^{+}, \mathrm{CD} 20^{+}, \mathrm{CD} 7 \mathrm{a}^{+}, \mathrm{CD} 5^{+}$, and $\mathrm{CD} 43^{+}$ in MCL $[41,42]$, as well as the sizes of nanoparticles in our experiments, thus CD20 and CD5 antigens will be chosen as the target spots of specific nanoprobes. It is reported that CD20 and CD5 antigens are usually located on the cytomembrane of MCL [43]. If CD20 and CD5 nanoprobes were used to specifically label CD20 and CD5 antigens on the cytomembrane of MCL, the diagnostic accuracy of MCL could be improved. Up to now, in vitro and in vivo specific imaging applications of CD20 and CD5 nanoprobes in MCL have rarely been reported. It is noteworthy that CD20 monoclonal antibody is also a prescription medicine (product name: Rituximab $^{\circledR}$ or MabThera ${ }^{\circledR}$ ). Rituximab induces cell lysis pharmacologically when it binds to CD20 antigen in B cells. Moreover, the introduction of rituximab can improve response rates when used in combination with standard chemotherapy for MCL [44-46].

In this communication, we report on the preparation of CD20 and CD5 nanoprobes and demonstrate the possibility of their application in specific fluorescent biolabels of MCL. Here, CD20 and CD5 nanoprobes are prepared from green/red-emitting $\mathrm{NaYF}_{4}: \mathrm{Yb}^{3+}, \mathrm{Er}^{3+}$ and blue-emitting $\mathrm{NaYF}_{4}: \mathrm{Yb}^{3+}, \mathrm{Tm}^{3+}$ nanoparticles. A direct oxidation method is used to convert hydrophobic nanoparticles into hydrophilic ones. CD20 and CD5 antibodies are utilized to couple the surfaces of the oxidized nanoparticles via EDC/NHS crosslinking agents. In vitro and in vivo upconversion luminescence imaging are measured to interpret the roles of both nanoprobes to play, which might provide a potential method for the specific biomedical diagnosis and targeted therapy of MCL in future.

\section{Materials and Methods}

2.1. Materials. $\mathrm{Er}_{2} \mathrm{O}_{3}$ (99.99\%), $\mathrm{Tm}_{2} \mathrm{O}_{3}$ (99.99\%), $\mathrm{Yb}_{2} \mathrm{O}_{3}$ (99.99\%), $\mathrm{Y}_{2} \mathrm{O}_{3}$ (99.99\%), 2-morpholinoethanesulfonic acid (MES, 99\%), N-(3-dimethylaminopropyl)- $\mathrm{N}^{\prime}$-ethylcarbodiimide hydrochloride (EDC.HCl, 98\%), N-hydroxysuccinimide (NHS, 98\%), and oleic acid (OA) were purchased from Shanghai Aladdin Reagent Inc. (Shanghai, China). $\mathrm{K}_{2} \mathrm{CO}_{3}, \mathrm{NH}_{4} \mathrm{~F}, \mathrm{NaOH}, \mathrm{K}_{2} \mathrm{HPO}_{4}, \mathrm{KH}_{2} \mathrm{PO}_{4}, \mathrm{KMnO}_{4}, \mathrm{NaIO}_{4}$, $\mathrm{HCl}$, cyclohexane, tert-butanol, acetone, methanol, and ethanol were of analytical grade and purchased from Sinopharm Chemical Reagent Co. Ltd. (Shanghai, China). CD20 (clone: 2H7) and CD5 (clone: UCHT2) monoclonal antibodies were purchased from BD Biosciences (San Jose, CA, USA). Secondary fluorescence antibodies FITC and Cy3 were goat anti-mouse, which were purchased from Wuhan Boster Bio-Engineering Limited Company (Wuhan, China). DAPI 
(4',6-diamidino-2-phenylindole, dihydrochloride) was also purchased from Wuhan Boster Bio-Engineering Limited Company. Jeko-1 and Raji cell lines were kindly provided by Professor Tadashi Yoshino, Department of Pathology, Okayama University (Japan). Female 5 weeks BALB/c nude mice were purchased from Beijing Weitong Lihua Experiment Animal Technology Co. Ltd. (Beijing, China).

2.2. Requisite Reagents. Lemieux-von Rudloff reagent: $0.0018 \mathrm{~g} \mathrm{KMnO}_{4}$ and $0.4494 \mathrm{~g} \mathrm{NaIO}_{4}$ were dissolved in $20 \mathrm{ml}$ deionized water according to the literatures $[47,48]$.

$\mathrm{K}_{2} \mathrm{CO}_{3}$ aqueous solution (5wt \%): $5.0 \mathrm{~g} \mathrm{~K}_{2} \mathrm{CO}_{3}$ was dissolved in $100 \mathrm{ml}$ deionized water.

Hydrochloric acid ( $\mathrm{pH}=4.0-5.0)$ : $\mathrm{HCl}$ was dropwise added into $50 \mathrm{ml}$ deionized water, and $\mathrm{pH}$ was adjusted to 4.0-5.0 with $\mathrm{HCl}$.

2.3. Synthesis of Oleate-Capped $\mathrm{NaYF}_{4}: \mathrm{Yb}^{3+}, \mathrm{Tm}^{3+}$ and $\mathrm{NaYF}_{4}: \mathrm{Yb}^{3+}, \mathrm{Er}^{3+}$ Nanoparticles. $\mathrm{NaYF}_{4}: \mathrm{Yb}^{3+}, \mathrm{Tm}^{3+}$ nanoparticles were synthesized using a solvothermal method described by $\mathrm{Li}$ et al. [49, 50]. Typically, according to its stoichiometry, $0.0127 \mathrm{~g} \quad \mathrm{Tm}_{2} \mathrm{O}_{3}, \quad 0.1180 \mathrm{~g} \quad \mathrm{Yb}_{2} \mathrm{O}_{3}$, and $0.3005 \mathrm{~g} \mathrm{Y}_{2} \mathrm{O}_{3}$ with cation molar ratio $\mathrm{Tm}^{3+} / \mathrm{Yb}^{3+} / \mathrm{Y}^{3+}=2$ / $18 / 80$ were dissolved in hot dilute hydrochloric acid and then heated to form white crystal. The crystal was mixed with $10 \mathrm{ml}$ deionized water, $10 \mathrm{ml}$ oleic acid (OA), and $10 \mathrm{ml}$ ethanol in a $50 \mathrm{ml}$ beaker. $0.1064 \mathrm{~g} \mathrm{NaOH}$ and $0.3943 \mathrm{~g}$ $\mathrm{NH}_{4} \mathrm{~F}$ were then added into the above mixture under vigorously stirring for 10 minutes. The feedstock was finally transferred to a $100 \mathrm{ml}$ Teflon-lined stainless autoclave, sealed, and heated to $190^{\circ} \mathrm{C}$ for $10 \mathrm{~h}$ in a muffle furnace. After naturally cooling to room temperature under ambient condition, sample was precipitated by centrifuging at $4000 \mathrm{rpm}$ for $15 \mathrm{~min}$ and discarding the supernatant. The obtained colloidal suspension was washed with cyclohexane, ethanol, and deionized water several times and then dried in atmosphere at $70^{\circ} \mathrm{C}$ overnight to form the final powder sample.

Moreover, $\mathrm{NaYF}_{4}: \mathrm{Yb}^{3+}, \mathrm{Er}^{3+}$ nanoparticles were prepared by the same route, except for $\mathrm{Er}_{2} \mathrm{O}_{3}$ instead of $\mathrm{Tm}_{2} \mathrm{O}_{3}$.

2.4. Converting Hydrophobic Nanoparticles into Hydrophilic Ones. Hydrophilic nanoparticles were prepared through direct oxidation of the carbon-carbon double bonds of the oleate ligands on particles' surfaces with the Lemieux-von Rudloff reagent to form the azelaic acid $\left(\mathrm{CH}_{2}\right)_{7}(\mathrm{COOH})_{2}$ reported by $\mathrm{Chen}$ et al. [48]. In brief, $0.1 \mathrm{~g}$ as-prepared $\mathrm{NaYF}_{4}: \mathrm{Yb}^{3+}, \mathrm{Tm}^{3+}$ nanoparticles, $100 \mathrm{ml}$ cyclohexane, $70 \mathrm{ml}$ tert-butanol, $10 \mathrm{ml}$ deionized water, and $5 \mathrm{ml} \mathrm{K}_{2} \mathrm{CO}_{3}$ aqueous solution were mixed and stirred for $20 \mathrm{~min}$ at room temperature. $20 \mathrm{ml}$ Lemieux-von Rudloff reagent was added dropwise in the resulting mixture and then stirred at $40^{\circ} \mathrm{C}$ for $48 \mathrm{~h}$. The product was washed with $5 \mathrm{ml}$ deionized water, $5 \mathrm{ml}$ acetone, and $5 \mathrm{ml}$ ethanol and then precipitated by centrifuging at $4000 \mathrm{rpm}$ for $15 \mathrm{~min}$. Subsequently, the product was treated with $50 \mathrm{ml}$ hydrochloric acid $(\mathrm{pH}=4.0-$ 5.0) for $30 \mathrm{~min}$. At last, the oxidized product was obtained by centrifugation, washed twice with deionized water, and dried at $70^{\circ} \mathrm{C}$ for $24 \mathrm{~h}$.
Moreover, hydrophilic $\mathrm{NaYF}_{4}: \mathrm{Yb}^{3+}, \mathrm{Er}^{3+}$ nanoparticles were also prepared by the same route.

2.5. Conjugation of Carboxylic-Capped Nanoparticles with CD20 and/or CD5 Antibodies. In brief, $0.0050 \mathrm{~g}$ carboxyliccapped $\mathrm{NaYF}_{4}: \mathrm{Yb}^{3+}, \mathrm{Tm}^{3+}$ nanoparticles were washed with $50 \mathrm{ml}$ MES buffer solution $(\mathrm{pH}=6.0)$. The resulting precipitate, $0.0050 \mathrm{~g} \mathrm{EDC} \cdot \mathrm{HCl}$, and $0.0150 \mathrm{~g}$ NHS were mixed in $20 \mathrm{ml}$ MES buffer solution ( $\mathrm{pH}=6.0$ ), stirred for $8 \mathrm{~h}$ at room temperature, and then precipitated by centrifuging at $4000 \mathrm{rpm}$ for $15 \mathrm{~min}$. The products were dispersed in $5 \mathrm{ml}$ PBS ( $p H=7.2)$. Subsequently, $50 \mu \mathrm{lCD} 20$ antibody was added in the $P B S(\mathrm{pH}=7.2)$ including the products and shaken on a shaker for $3 \mathrm{~h}$ at room temperature. After washing with deionized water twice, CD20-nanoprobes were stored in $1 \mathrm{ml} \mathrm{PBS}(\mathrm{pH}=7.2)$ at $4^{\circ} \mathrm{C}$.

Moreover, CD5 nanoprobes were also prepared by the same route, except for $\mathrm{CD} 5$ antibody and $\mathrm{NaYF}_{4}: \mathrm{Yb}^{3+}, \mathrm{Er}^{3+}$ nanoparticles instead of CD20 antibody and $\mathrm{NaYF}_{4}: \mathrm{Yb}^{3+}$,$\mathrm{Tm}^{3+}$ nanoparticles.

2.6. Cell Culture, Hybridization In Situ, and In Vitro Upconversion Fluorescence Imaging. Cells were cultured on RPMI1640 containing $15 \%$ bovine serum in a $5 \% \mathrm{CO}_{2}$ incubator at $37^{\circ} \mathrm{C}$. The logarithmic growth phase cells were taken to use in experiments. $50 \mu \mathrm{l}$ Jeko- 1 or Raji cell suspension (cell density: $2 \times 10^{6} / \mathrm{ml}$ ) was on slide glass at $800 \mathrm{rpm}$ for $5 \mathrm{~min}$ and washed with $P B S(\mathrm{pH}=7.2)$ twice after cell fixation with acetone for $5 \mathrm{~min}$. For single-label imaging, Raji cells on slide glass were hybridized in situ with $40 \mu \mathrm{l} \mathrm{CD} 20$ nanoprobes at $37^{\circ} \mathrm{C}$ for $1 \mathrm{~h}$. For doublelabel imaging, Jeko-1 cells on slide glass were hybridized in situ with $40 \mu \mathrm{l}$ CD20 nanoprobes and $40 \mu \mathrm{l}$ CD5 nanoprobes at $37^{\circ} \mathrm{C}$ for $1 \mathrm{~h}$. After washing the cells with $P B S$ $(\mathrm{pH}=7.2)$ three times to remove the excess nanoprobes, in vitro upconversion fluorescence imaging was carried out on a Nikon Eclipse Ti-S inverted fluorescence microscope equipped with a $980 \mathrm{~nm}$ laser.

2.7. The Effect of Antibody Dose on In Vitro Upconversion Fluorescence Imaging. In addition to adding 15, 20, and $40 \mu \mathrm{l} \mathrm{CD} 20$ and CD 5 antibodies each time in three groups of Jeko- 1 cells, the cultural course of cells is similar to Section 2.6. Briefly, Jeko-1 cells on slide glass in each group were hybridized in situ with $40 \mu \mathrm{l}$ CD20 nanoprobes and $40 \mu \mathrm{l}$ CD5 nanoprobes after cultured for 5 days. In vitro upconversion fluorescence imaging was carried out under a $980 \mathrm{~nm}$ laser excitation after washing the cells with $\mathrm{PBS}(\mathrm{pH}=7.2)$ three times to remove the excess nanoprobes.

2.8. Transplanted Cancer Model in Nude Mice, In Vivo Upconversion Fluorescence Imaging. Subcutaneous cancer formation was under way after the purchased nude mice had been cultured for one week. Six nude mice in each group were inoculated subcutaneously Jeko-1 cell suspension $\left(2 \times 10^{6} / \mathrm{ml}, 0.2 \mathrm{ml} /\right.$ single $)$ in the right back of nude mice. On day 20 of inoculation, tumorigenesis was obviously observed. After $0.2 \mathrm{ml}(350 \mu \mathrm{g} / \mathrm{ml})$ CD20 and CD5 nanoprobes had been, respectively, injected into the tail vein of cancer mice models, the mice were placed in the feeding 


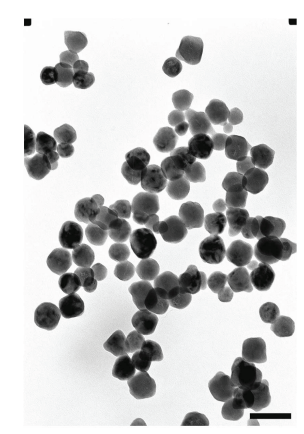

(a)

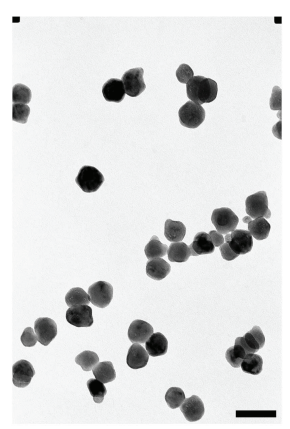

(b)

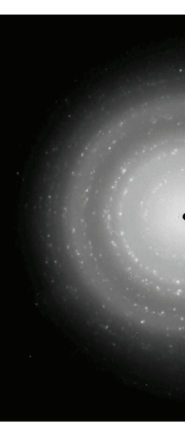

(c)

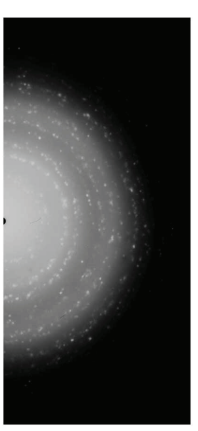

(d)

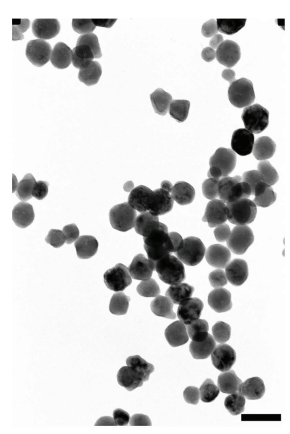

(e)

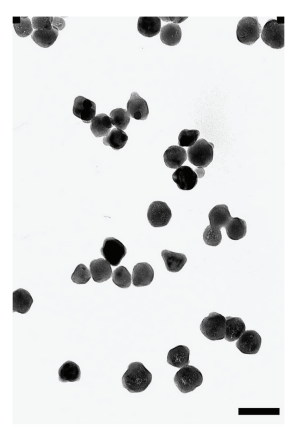

(f)

Figure 1: TEM images of hydrophobic (a, e) and hydrophilic (b, f) sample 1 and 2 after filtered by $0.22 \mu \mathrm{m}$ filter, as well as corresponding SAED patterns $(c, d)(80 \mathrm{~K} \times, 1 \mathrm{bar}=100 \mathrm{~nm})$.

box to continue cultivating. When we decided to measure in vivo upconversion fluorescence imaging, the mice were placed in the anesthesia device for initial anesthesia. Controlling the anesthetic gas flow of isoflurane to the right amount (1-1.5 scale), the mice on specimen stage of small animal fluorescence imaging system maintain anesthesia. A fluorescence imaging workflow of cancer model mice in this system was automatically accomplished by starting the regular measurement program.

2.9. Characterization. The detailed characterization processes are shown in the supplemental data I.

\section{Results and Discussion}

3.1. Structure and Upconversion Luminescence of Nanoparticles. Here, $\mathrm{NaYF}_{4}: \mathrm{Yb}^{3+}, \mathrm{Tm}^{3+}$ and $\mathrm{NaYF}_{4}: \mathrm{Yb}^{3+}$, $\mathrm{Er}^{3+}$ are designated as sample 1 and 2. Two samples are characterized by XRD, TEM, and fluorescence spectrophotometer to evaluate their phase composition, morphology, and fluorescence property. Figure S1 of supplemental data II shows the XRD patterns of sample 1 and 2. Compared to the standard patterns of cubic $\mathrm{NaYF}_{4}$ (JCPDS number: 06-0342) and hexagonal $\mathrm{NaYF}_{4}$ (JCPDS number: 28-1192), the XRD data of two samples suggest that they are the mixed crystals of cubic and hexagonal structures, where cubic phase compositions in the two samples are $78.5 \%$ and $74.9 \%$, respectively. Hydrophobic sample 1 and sample 2 after filtered by a $0.22 \mu \mathrm{m}$ MILLEX $^{\circledR}$ GP Filter Unit show the agglomerated particles with ellipse-like and dissymmetrical hexagonal shapes in Figures 1(a), 1(e) in ethanol. The most probable diameters of the size distributions for hydrophobic sample 1 and 2 are $57.4 \pm 0.4$ and $59.7 \pm 0.4 \mathrm{~nm}$ with the FWHMs of 16.3 and $18.7 \mathrm{~nm}$ in Figure S2. After oxidized further by the Lemieux-von Rudloff reagent, hydrophilic sample 1 and sample 2 in Figures 1(b), 1(f) show better dispersibility. The selected area electron diffraction (SAED) patterns in Figure 1(c), 1(d) show that two samples have same multiple diffraction rings, which indicate that the as-synthesized nanoparticles are polycrystalline.

Figure $\mathrm{S} 3$ is the characteristic upconversion luminescence spectra of sample 1 and 2 under a $980 \mathrm{~nm}$ laser excitation at room temperature, in where sample 1 emits purple and blue luminescence at 361 and $477 \mathrm{~nm}$ with laser pump power density of $6.8 \times 10^{2} \mathrm{~W} / \mathrm{cm}^{2}$; sample 2 emits green and red upconversion luminescence at 540 and $657 \mathrm{~nm}$ with power density of $1.5 \times 10^{1} \mathrm{~W} / \mathrm{cm}^{2}$. According to the literature [51], their dependences of the integrated upconversion luminescence intensities on laser pump powers in Figure S4 indicate that purple and blue fluorescence at 361 and $477 \mathrm{~nm}$ from $\mathrm{Tm}^{3+}$ ions are four- and three-photon processes; green and red upconversion fluorescence at 540 and $657 \mathrm{~nm}$ from $\mathrm{Er}^{3+}$ ions are two-photon upconversion process, respectively. The upconversion mechanisms of sample 1 and 2 are shown in Figure S5 and explained in supplemental data III. Moreover, two samples exhibit a stronger light stability or resistance to photobleaching in Figure S6 because inorganic host materials can provide a rigid crystalline environment for the dopant ions to achieve stable upconversion luminescence and further can keep the dopant ions off outer environments. Thus, both samples are suitable for bicolor upconversion fluorescence cores of CD20 and CD5 nanoprobes.

3.2. Surface Oxidation of Hydrophobic Ligands and Bioconjugation of Nanoprobes. It is well known that the surfaces of most as-prepared inorganic nanoparticles lack active functional groups or ligands so that they are difficult to bind to biological molecules for biolabel applications. It is therefore necessary to couple the particles' surfaces with active functional groups in order to improve the capability of conjugation with biomolecules. Figure S7 is the schematic illustration of surface oxidation and bioconjugation of nanoprobes.

To prepare the CD20 and CD5 nanoprobes, both samples should be firstly converted from hydrophobicity to hydrophilicity when they have been synthesized in oil phase. The particles' surfaces of samples have been coated by the oleate ligands when $\mathrm{OA}$ is used as nonaqueous solvent in our experiments. To convert hydrophobic inorganic nanoparticles into hydrophilic ones, the Lemieux-von Rudloff oxidation method [47] is utilized to selectively oxidize the carbon-carbon double bonds $\left(\mathrm{R}-\mathrm{HC}=\mathrm{CH}-\mathrm{R}^{\prime}\right)$ of the oleate ligands on the particles' surfaces with $\mathrm{KMnO}_{4}$ in the Lemieux-von Rudloff reagent to form azelaic acid containing carboxyl groups $(-\mathrm{COOH})[47,48]$. In FT-IR spectra of the two oxidized samples in Figure S8, carboxyl groups can be obviously confirmed from the characteristic absorption 


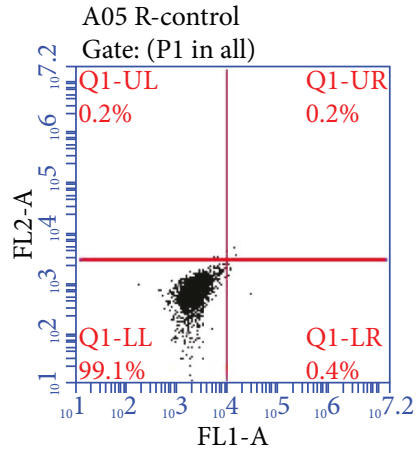

(a)
A02 FITC

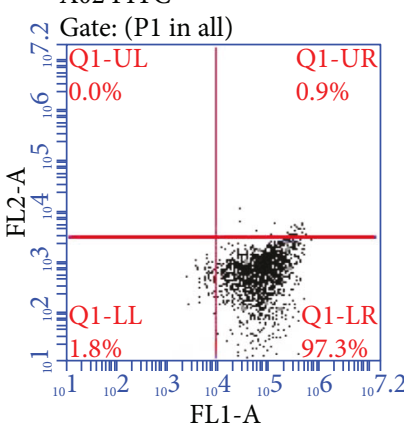

(b)

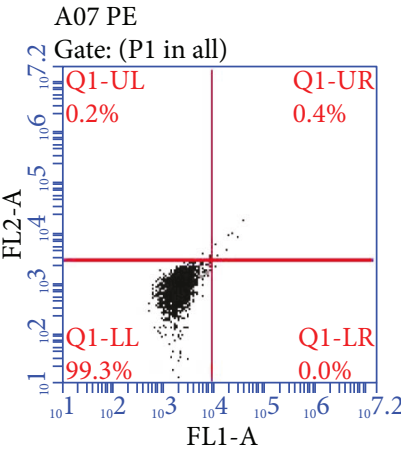

(c)

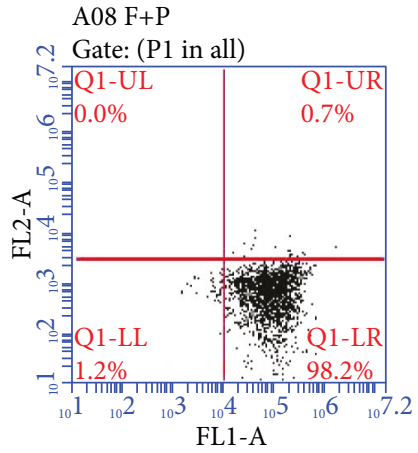

(d)

Figure 2: Isotypes of Raji cells. Control (a), FITC-CD20 (b), PE-CD5 (c), and FITC-CD20/PE-CD5 (d).

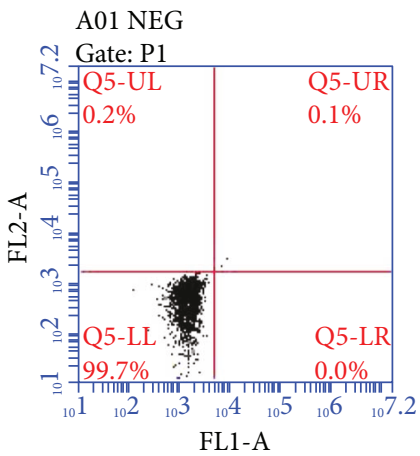

(a)

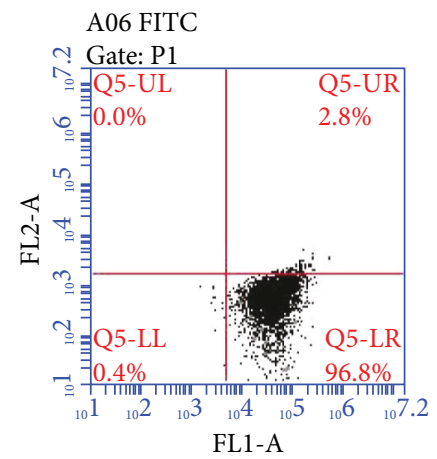

(b)

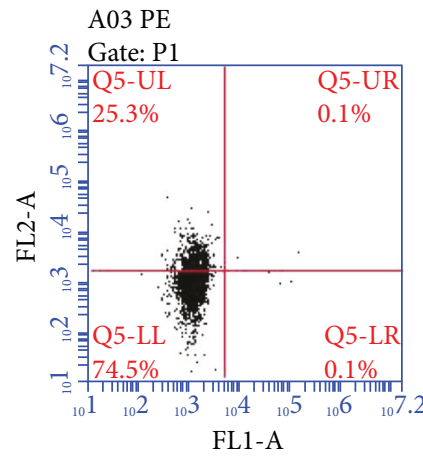

(c)

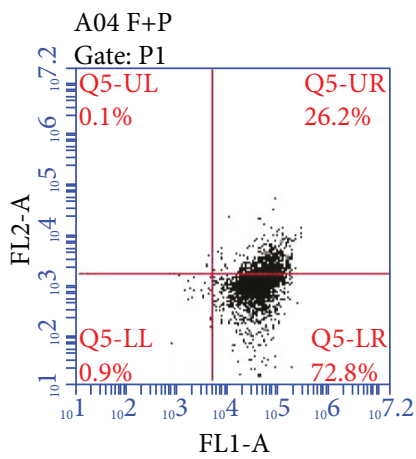

(d)

FIGURE 3: Isotypes of Jeko-1 mantle cells. Control (a), FITC-CD20 (b), PE-CD5 (c), and FITC-CD20/PE-CD5 (d).

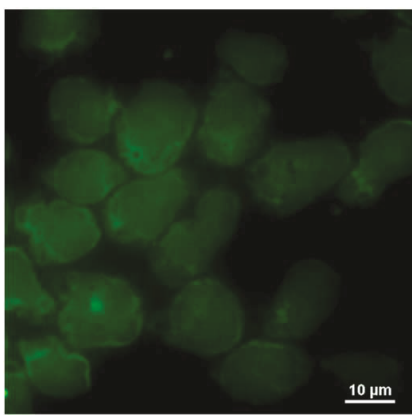

(a)

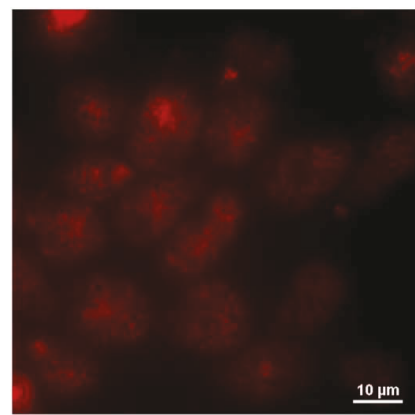

(b)

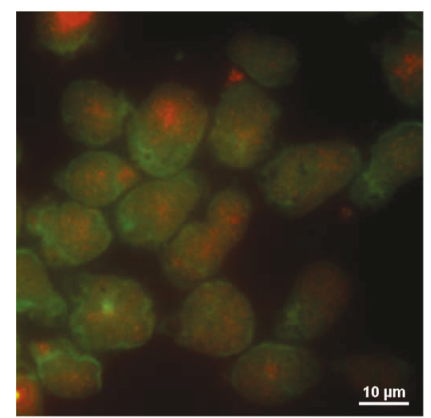

(c)

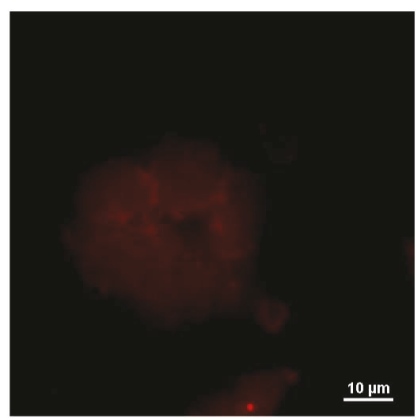

(d)

Figure 4: Double-labeled immunofluorescence images of Jeko-1 and Raji cells. The FITC (green) label (a) corresponds to CD5 marker, the Cy3 (red) (b) to CD20 marker, and their overlay (c) of Jeko-1 cells, as well as the Cy3 (red) (d) to CD20 marker of Raji cells $(40 \times, 1 \mathrm{bar}=10 \mu \mathrm{m})$.

bands at 1633 and $1746 \mathrm{~cm}^{-1}$ (the stretching vibration of $\mathrm{C}=\mathrm{O}$ ), as well as $3418 \mathrm{~cm}^{-1}$ (the stretching vibration mode of $\mathrm{O}-\mathrm{H}$ ) [48]. Compared with an absorption band at $2975 \mathrm{~cm}^{-1}$ of two samples, the absorption band disappearance of the two oxidized samples indicates the cleavage of the $-\mathrm{HC}=\mathrm{CH}$ - group because the band is attributed to the $=\mathrm{C}-\mathrm{H}$ stretching vibration [48], implying that the carboncarbon double bonds of the oleate ligands have been oxidized. It must be emphasized here that $\mathrm{NaIO}_{4}$ content in Lemieux-von Rudloff reagent must be far beyond $\mathrm{KMnO}_{4}$ because, on the one hand, $\mathrm{MnO}_{4}^{-}$is only oxidant which oxidizes the carbon-carbon double bonds of the oleate ligands; on the other hand, the excess acidic group of periodate $\left(\mathrm{IO}_{4}^{-}\right)$plays an important role in reoxidizing low valence $\mathrm{Mn}$ ions to reusable $\mathrm{MnO}_{4}^{-}$. If $\mathrm{NaIO}_{4}$ content is lower, $\mathrm{KMnO}_{4}$ oxidizes the carbon-carbon double bonds for $48 \mathrm{~h}$ to produce yellow brown $\mathrm{MnO}_{2}$ precipitation, as shown in Figure S9(a), which is difficult to be separated from two samples. Contrarily, the oxidation reaction of $\mathrm{KMnO}_{4}$ to the carbon-carbon bonds will go on until the 


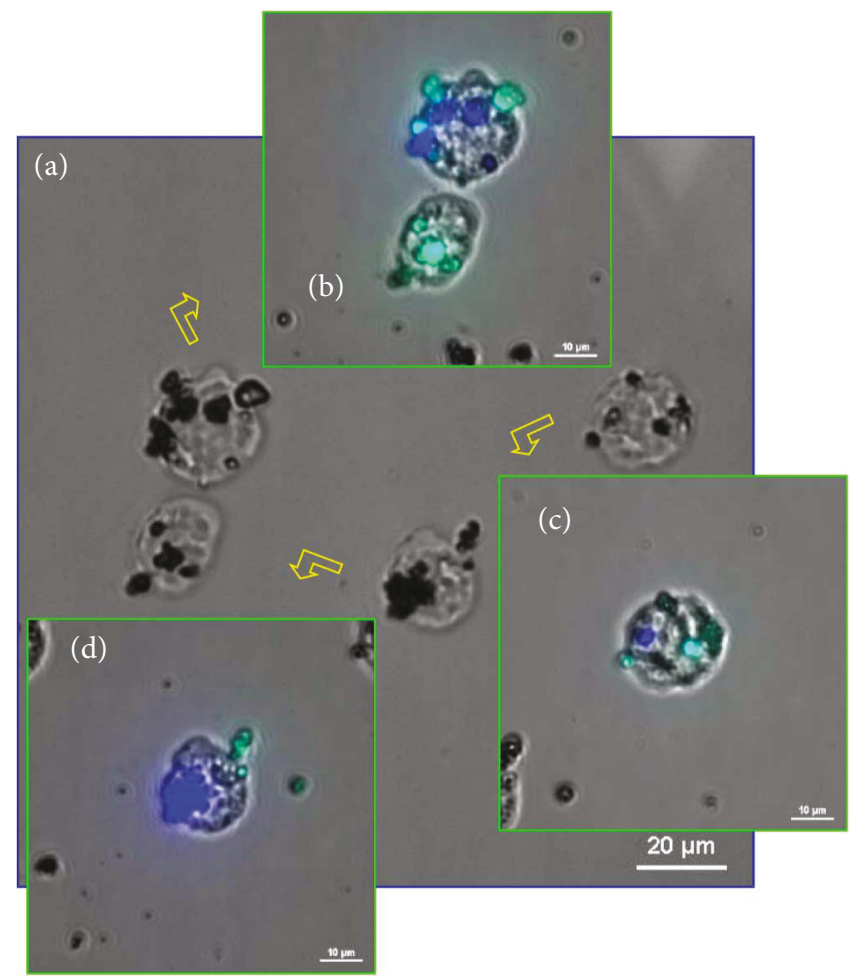

Figure 5: Bright field image (a) of Jeko-1 cells $(20 \times, 1 \mathrm{bar}=20 \mu \mathrm{m})$ and their overlays of blue/green (b-d) double-labeling upconversion fluorescence under a $980 \mathrm{~nm}$ laser excitation $(40 \times, 1 \mathrm{bar}=10 \mu \mathrm{m})$. The punctate blue/green upconversion fluorescence comes from CD20 and CD5 nanoprobes, showing the existence of CD20 and CD5 antigens on the Jeko-1 cells and contributing to the identification of mantle cell lymphoma from B-cell lymphoma.

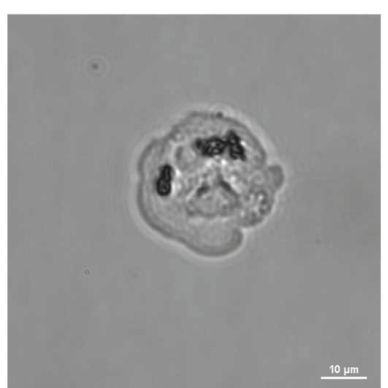

(a)

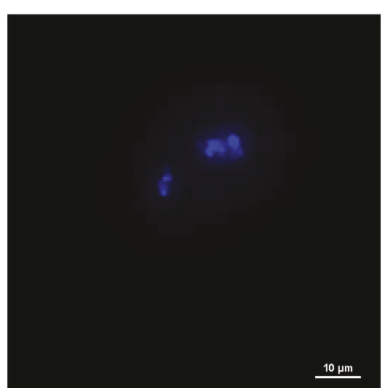

(b)

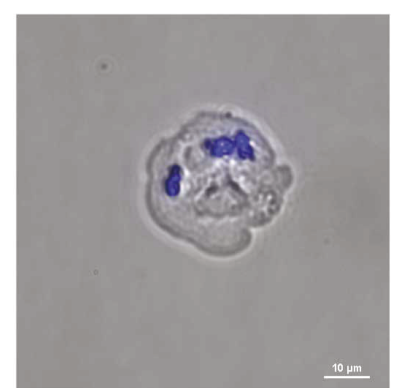

(c)

FIGURE 6: Bright field (a) and blue single-labeling upconversion fluorescence (b) images of Raji cells, as well as the overlay (c) under a $980 \mathrm{~nm}$ laser excitation $(40 \times, 1$ bar $=10 \mu \mathrm{m})$.

reaction is over. Here, there is not $\mathrm{MnO}_{2}$ precipitation in the plum solution in Figure S9(b).

Moreover, upconversion emission intensities of the oxidized samples, as shown in Figure S10, have been enhanced at blue and green emission, which are beneficial to such biomedicine applications as bicolor fluorescence labeling. The upconversion enhancement mechanism is approximatively similar to those of the core-shell type upconversion nanoparticles from our previous works [52-54] and is simply explained in supplemental data III.

Subsequently, a coupling method of the oxidized samples through EDC/NHS crosslinking agents with CD20 and CD5 antibodies was used to prepare CD20 and CD5 nanoprobes in our experiment. It is well known that EDC is a watersoluble carbodiimide crosslinker for zero-length carboxylto-amine conjugation; NHS can improve the efficiency of EDC coupling reactions or create amine-reactive regents [55]. (The references to the function of EDC and NHS crosslinking agents are referred to the web version.) Here, bioconjugation of the oxidized samples is accomplished by (i) proportionally mixing EDC and NHS with the oxidized samples and stirring them and (ii) adding proper amount of CD20 and CD5 monoclonal antibodies to them and shaking them. It must be also emphasized that the oxidized sample 1 and 2 are biologically coupled with CD20 and $\mathrm{CD} 5$ monoclonal antibodies to perform $\mathrm{CD} 20$ and 


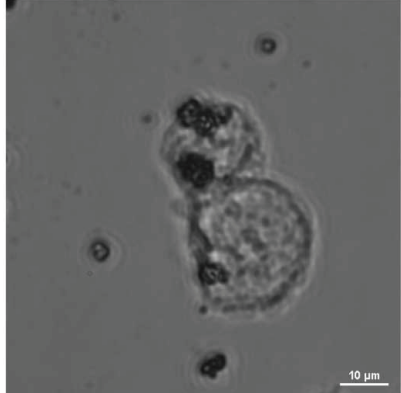

(a)

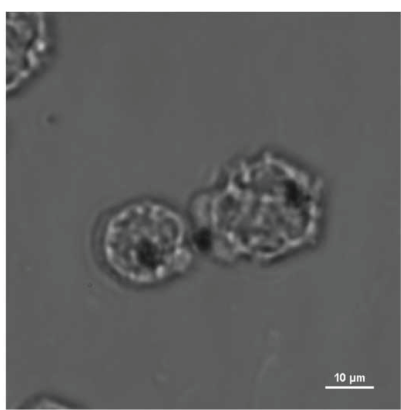

(e)

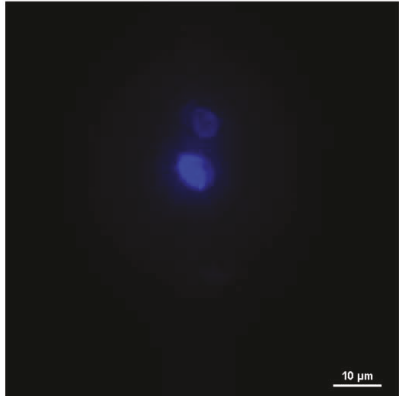

(b)

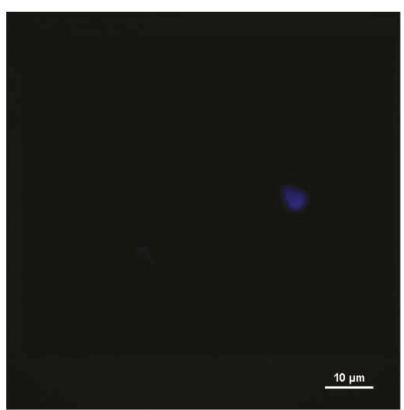

(f)

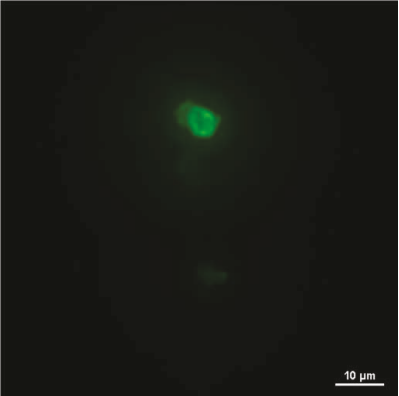

(c)

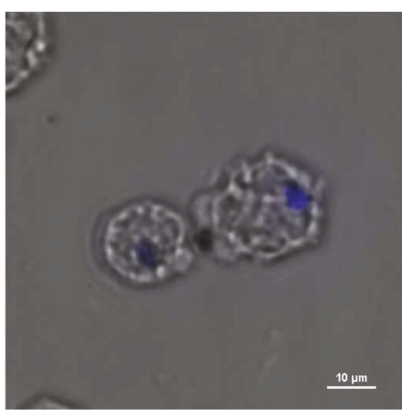

(g)

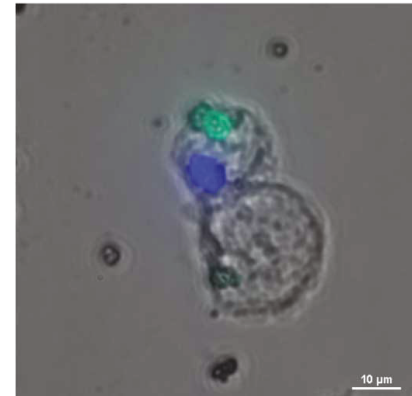

(d)

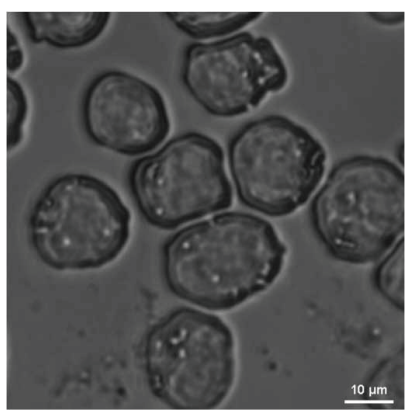

(h)

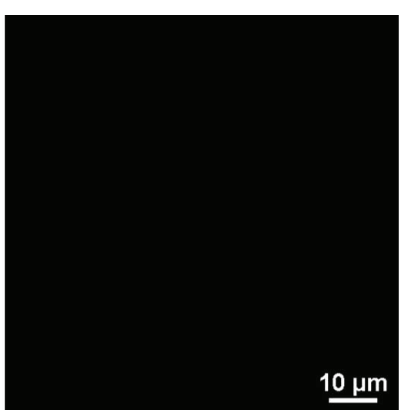

(i)

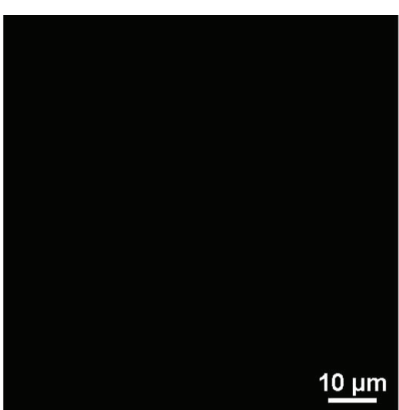

(j)

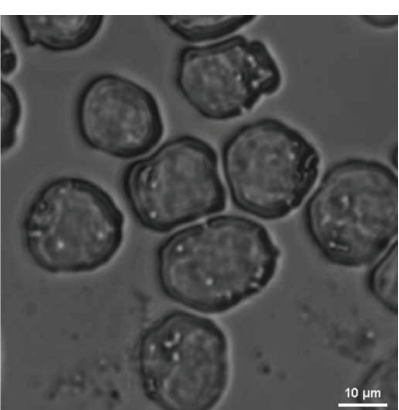

(k)

FIgURE 7: The effect of antibody dose in cell culture on in vitro upconversion fluorescence imaging under a $980 \mathrm{~nm}$ laser excitation $(40 \times$, $1 \mathrm{bar}=10 \mu \mathrm{m})$, where $15(\mathrm{a}-\mathrm{d}), 20(\mathrm{e}-\mathrm{g})$, and $40 \mu \mathrm{l}(\mathrm{h}-\mathrm{k})$ CD20 and CD 5 antibodies are fed each time for 5 days' cell culture, respectively.

CD5 nanoprobes, respectively. Under a $980 \mathrm{~nm}$ laser excitation, two nanoprobes indeed show blue and green/red fluorescence in Figure S11. If CD20 and CD5 nanoprobes are hybridized in situ with MCL, CD20, and CD5 antibodies should be in response to CD20 and CD5 antigens on the cytomembrane of MCL according to the interaction rule of antigens with their specific antibodies. Blue and green/ red photoluminescence from $\mathrm{CD} 20$ and $\mathrm{CD} 5$ nanoprobes should reflect the presence of CD20 and CD5 antigens. Note that (i) it is necessary to strictly control acidic or alkaline conditions in the bioconjugation processes because the activation of the carboxyl groups with EDC/NHS is in acidic environment, whereas the coupling of an antibody (such as CD20 or CD5) or a protein through EDC/NHS requires alkaline condition. Here, buffer $\mathrm{pH}$ plays an important role in the bioconjugation procedure. The surfacecrosslinked process is achieved by electrostatic attraction between carboxyl capped on the sample surface and the amino group of antibody or protein. The positive charge of the amino group and the negative charge of carboxyl group require an adapted buffer $\mathrm{pH}$. Thus, the role of buffer $\mathrm{pH}$ is optimal reaction condition [56]. (ii) Jeko-1 cell lines are MCL containing CD20 and CD5 antigens $[41,42]$. Raji cell lines are Burkitt lymphoma including CD20 antigen without CD5 [57-59]. Because these cell lines are suspension cells without anchorage-dependent cells, they must be spun on slide glass to hybridize in situ with CD20 and CD5 nanoprobes and further incubate for bicolor fluorescence imaging.

3.3. In Vitro Bicolor Upconversion Fluorescence Imaging of $M C L$. In order to theoretically explain the immunofluorescence phenomena and our experiment results, Jeko-1 and Raji cell lines were stained with CD20 and CD5 and analyzed by flow cytometry and immunohistochemistry. (i) Flow cytometry is used to define the presence of CD5 and CD20 antigens in Jeko- 1 and Raji cells and then monitor their positive expression rates. In this experiment, CD20 and CD5 expressions in Jeko-1 and Raji cells were detected using FITC-conjugated monoclonal mouse anti-human CD20 
and PE-conjugated monoclonal mouse anti-human CD5. Figures 2 and 3 give the isotypes of Raji and Jeko- 1 cells. The positive expression rates of single CD20 and CD5 in Raji cells in Figure 2 are 98.2 and $0.6 \%$; the positive rates of double CD20 and CD5 expressions are 98.9 and $0.7 \%$. So, CD20 expression in Raji cells is positive; CD5 expression is negative, which accord well with the immunophenotypes of Burkitt lymphoma. Conversely, CD20 and CD5 expressions in Figure 3 are positive in Jeko-1 mantle cells, in where the positive expression rates of single CD20 and CD5 are 99.6 and 25.4\%; the positive rates of double CD20 and CD5 expressions are 99.0 and $26.3 \%$. Although the positive expressions rates of single CD20 and CD5 in Jeko- 1 mantle cells are similar to those of double CD20 and CD5, the positive expression rates of double CD20 and CD5 have more realistic significance in the routine pathological diagnosis. This is due to a fact that several kinds of inflammatory cells could be observed in the microenvironment of MCL in the pathological diagnosis or experimental procedure during MCL nude mice model, including $\mathrm{CD} 20^{+}$phenotypic normal $\mathrm{B}$-cells and $\mathrm{CD}^{+}$phenotypic normal precursor T-cells. MCL is one of the most difficult to treat B-cell non-Hodgkin lymphomas. MCL diagnosis is based on morphology and immunophenotyping $\left(\mathrm{CD} 20^{+}, \mathrm{CD}^{+}, \mathrm{CD}^{2} 3^{-}\right.$, and $\left.\mathrm{FMC}^{+}\right)$. It is difficult to distinguish $\mathrm{CD}_{2} 0^{+}$normal B-cells and $\mathrm{CD}^{+}$ normal T-cells with the MCL tumor cells using single antibody. So, the simultaneous positive expressions of double antibodies could contribute to distinguishing the reactive inflammatory cells in the background of MCL with the tumor cells of MCL. (ii) Immunocytofluorescent (ICF) technique is also used to detect the expression status of CD20 and CD 5 on Jeko-1 and Raji cell lines. Here, CD5 is labeled with FITC (green); $\mathrm{CD} 20$ is labeled with $\mathrm{Cy} 3$ (red). Figure 4 is the double-labeled immunofluorescence images of Jeko-1 and Raji cells. The images show that both green and red fluorescence can be observed on the membrane surfaces of Jeko-1 cells. However, only red fluorescence is observed on Raji cell membrane. The results are the same with the experiment results in Figures 2 and 3, as well as the literatures [41, 42, 57-59]. Compared with single antibody, more specific positive expressions of double antibodies thus should improve the detection probability of tumors in the routine pathological diagnosis.

After Jeko-1 cells have been labeled with both CD20 and CD5 nanoprobes, the labeled cells are observed using the inverted fluorescence microscope. Figure 5 is blue/green double-labeling upconversion fluorescence images of Jeko-1 cells. The images show that a lot of tumor cells are labeled with blue fluorescence, which is connected with CD20 marker; many tumor cells are labeled with green fluorescence, which is connected with CD5 marker. The results indicate that the Jeko- 1 cells can express CD20 and CD5 markers by blue/green double-labeling upconversion fluorescence. Seafoam/lapis fluorescence in Figures 5(b)-5(d) could result from the proportion difference of the mixture of green/blue fluorescence. Each bicolor upconversion fluorescence image can precisely overlay its corresponding bright field image in Figures 5(b)-5(d). Here, original bright field and blue/green upconversion fluorescence images of Jeko-1 cells, as well as

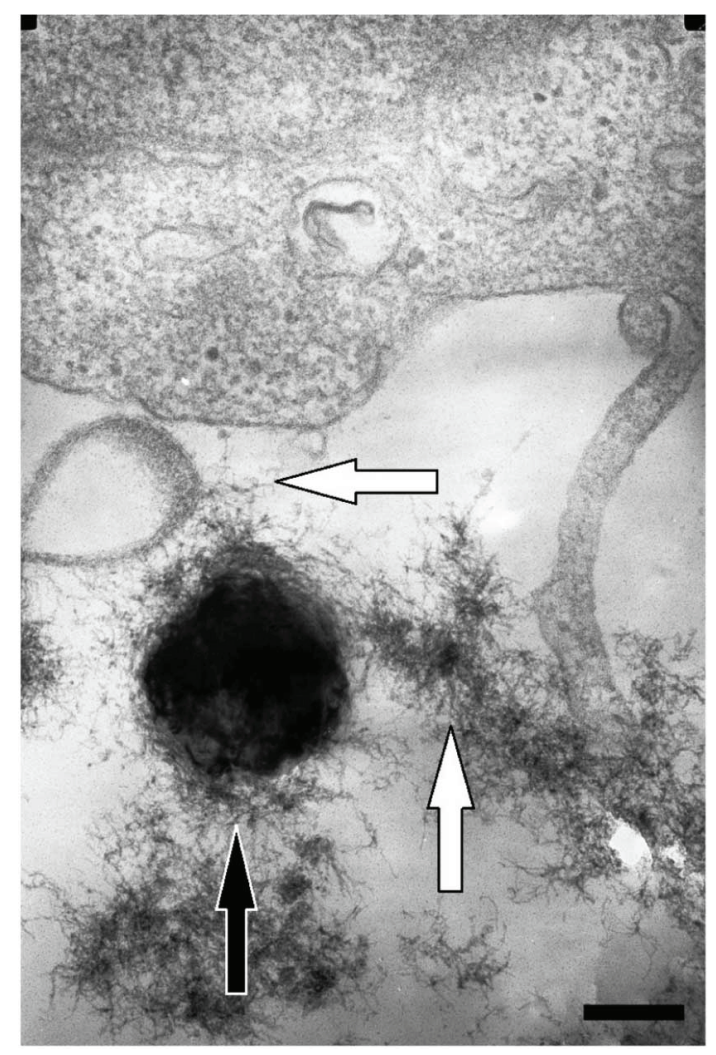

FIgUre 8: TEM image of Jeko-1 cells hybridized with CD20 and CD5 nanoprobes $(40 \mathrm{~K} \times, 1 \mathrm{bar}=200 \mathrm{~nm})$. Black and white arrows indicate a CD20 and/or CD5 nanoprobe and some filamentous fibers, respectively.

their overlays are shown in Figure S12-S15. Furthermore, Raji cells are also labeled with the two coupled nanoprobes to detect the expression status of CD20 and CD5. Only blue fluorescence connected with CD20 marker is observed in Figure 6. More blue/green double-labeling upconversion fluorescence images of Jeko-1 cells, as well as blue singlelabeling upconversion fluorescence images of Raji cells are also shown in Figure S16-S19. Therefore, just like the effect of double antibodies' stain in Figures 2 and 3, CD20 and CD5 nanoprobes in this experiment could be used for more specific bicolor fluorescence labeling and cellular imaging in vitro.

Whether or not CD20 and CD5 nanoprobes would possess specificity for Jeko-1 cells is an important issue of great concern to us. A confirmatory method is presented for the determination of antigen dependence of antibody labeled nanoprobe by measuring upconversion luminescence of the tumor cells with different expression levels of antigens. Based on specific antigen-antibody recognition, the expression levels of CD20 and/or CD5 antigens on Jeko-1 cell surface in this experiment can be adjusted by means of feeding different doses of CD20 and CD5 antibodies in cell culture to consume corresponding CD20 and/or CD5 antigens on Jeko-1 cells. After hybridized in situ with CD20 and/or CD5 nanoprobes, in vitro upconversion fluorescence of the labeled Jeko- 1 cells is observed under a $980 \mathrm{~nm}$ laser excitation. Figure 7 shows the effect of antibody dose in cell culture 


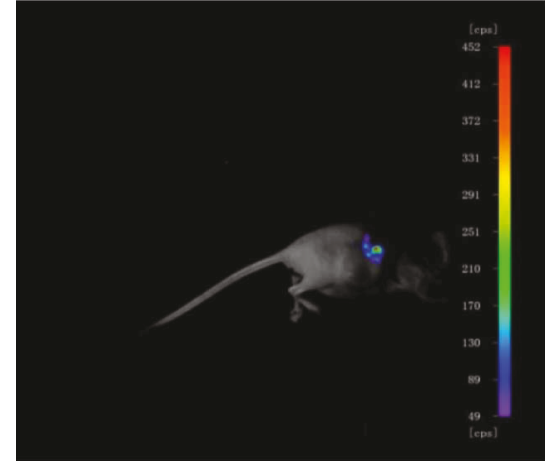

(a)

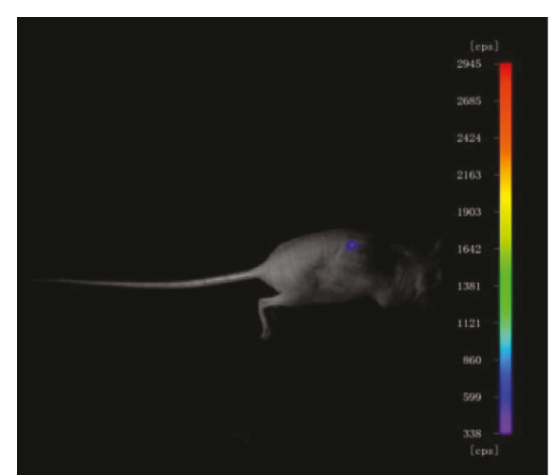

(b)

FIGURE 9: In vivo upconversion fluorescence images of CD20 (a) and CD5 (b) nanoprobes into nude mouse models of Jeko-1 cells under a $980 \mathrm{~nm}$ laser excitation.

on in vitro upconversion fluorescence imaging, namely, with the feeding dose increase of CD20 and CD5 antibodies in cell culture, blue/green double color upconversion fluorescence (b, c) turns into single color one (f) and even disappearance $(\mathrm{i}, \mathrm{j})$; their corresponding upconversion fluorescence intensities gradually drop to none $(b, c) \rightarrow(f) \rightarrow(i, j)$. The more the feeding doses of CD20 and CD5 antibodies, the lower the expression levels of CD20 and/or CD5 antigens on Jeko-1 cell surface, the weaker the fluorescence labeling effect of CD20 and CD5 nanoprobes. This observation suggests that the bi/single color upconversion fluorescence labeling effect of CD20 and/or CD5 nanoprobes on Jeko-1 cells in this experiment is inversely proportional to the feeding dose of CD20 and/or CD5 antibodies and is proportional to the expression levels of CD20 and/or CD5 antigens on Jeko-1 cell surface. The result proves high specificity of CD20 and CD5 nanoprobes for Jeko-1 cells.

It is well known that CD20 and CD5 antigens are usually located on the cytomembrane of Jeko- 1 cells. Could CD20 and CD5 nanoprobes either penetrate into or adhere to the cytomembrane of Jeko-1 cells in our experiments? Here, TEM image of Jeko- 1 cells hybridized with CD20 and CD5 nanoprobes in Figure 8 gives us morphologic evidence that a nanoprobe (see black arrow) binds itself to the microvillus and cytomembrane of Jeko- 1 cells through a lot of irregular filamentous fibers (see white arrows). We deduce that, on the one hand, the nanoprobe could be made up of several upconversion nanoparticles; on the other hand, these filamentous fibers could be some organics containing ligands and active functional groups such as CD20 and CD5 antibodies. The TEM image shows the spatial relationship of Jeko-1 cells and both CD20 and CD5 nanoprobes. If the specific CD20 and CD5 nanoprobes were loaded with antitumor drugs, these nanoprobes would be regarded as a novel "nano-biomissile" not only to label, diagnose, and track the tumor cells but also to inhibit and kill them and even to observe the prognosis. This presupposition might be doable according to the spatial relationship in Figure 8 , indicating that MCL could be treated and cured by CD20 and CD5 nanoprobes loaded with the antibody drugs such as Rituximab.
3.4. In Vivo Upconversion Fluorescence Imaging of Transplanted Cancer Model. CD20 and CD5 nanoprobes are, respectively, injected into nude mouse models via the caudal vein to observe in vivo upconversion fluorescence imaging of both nanoprobes in the mouse models. After $2 \mathrm{~h}$, the mouse models are continuously anesthetized by isoflurane using an oral anesthesia device. The anesthetized mouse models are then placed into a camera obscura to take their upconversion fluorescence imaging when under a $980 \mathrm{~nm}$ laser irradiation. Figure 9 is in vivo upconversion fluorescence images of CD20 and CD5 nanoprobes in mouse models. Here, irregular multicolored spots are clearly observed on the back of the mouse models, indicating that CD20 and/or CD5 nanoprobes have been specifically labeled on Jeko-1 cells in nude mouse models. As well known, multiple pseudocolors and their areas on light-emitting part of test specimen in small animal fluorescence imaging system only reflect the changes of fluorescence intensity in a certain range instead of true color of the fluorescence in nature. Thus, the multicolored fluorescence spots in size in Figure 9 might be determined by the distribution of Jeko-1 cells in the mouse models, which is due to higher positive expression of CD20 and CD5 antigens in MCL.

3.5. Prospect. Correct identification of different cells is an important task for biomedical diagnosis and treatment. Such nanotechnology as upconversion luminescence imaging might provide us a prospective method to identify a particular cell type such as stem cells or cancer cells due mainly to the advantages of a safe excitation mode of upconversionbased nanoprobes and the "optical window" of biological tissues. As long as the upconversion-based nanoparticles are conjugated with different cell-targeting molecules [19-36], the nanoparticles can become specific nanoprobes to identify a particular cell type such as stem cells or cancer cells and even achieve the targeted therapy in future.

\section{Conclusions}

In conclusion, we report the preparation of CD20 and CD5 nanoprobes and their specific identification application in 
MCL. A production procedure was present as follows: (i) the synthesis of $\mathrm{NaYF}_{4}: \mathrm{Yb}^{3+}, \mathrm{Tm}^{3+}$ and $\mathrm{NaYF}_{4}: \mathrm{Yb}^{3+}, \mathrm{Er}^{3+}$ nanoparticles; (ii) the oxidation of the carbon-carbon double bonds of the oleate ligands; and (iii) the coupling through EDC/NHS crosslinking agents with CD20 or CD5 antibody to the hybridization in situ with MCL. This procedure is extremely facile. The capability of high-specific optical imaging of CD20 and CD5 nanoprobes in MCL provides promise for their wide application in specific identification.

\section{Conflicts of Interest}

The authors declare that there is no conflict of interests regarding the publication of this paper.

\section{Acknowledgments}

The authors thank B.M. Heran Yang for tentative experiments on cell culture and hybridization in situ. This work was supported by grants from the Natural Science Foundation of Heilongjiang Province of China (Grant no. H2017074).

\section{Supplementary Materials}

Supplemental data I: characterization. Supplemental data II: graphics. Figure S1: XRD patterns of samples. Figure S2: the size distributions of hydrophobic sample 1 and 2 counted over 300 particles. Gaussian fits give the most probable diameters of $57.4 \pm 0.4$ and $59.7 \pm 0.4 \mathrm{~nm}$ with the FWHMs of 16.3 and $18.7 \mathrm{~nm}$ for them. Figure S3: upconversion luminescence spectra of samples under a $980 \mathrm{~nm}$ laser excitation. Figure S4: double logarithmic plots of the integrated upconversion luminescence intensities at different wavelengths from $\mathrm{Er}^{3+}$ and $\mathrm{Tm}^{3+}$ ions as a function of pump powers. The solid lines are of linear fit. Figure S5: energy level diagram of $\mathrm{Tm}^{3+}, \mathrm{Yb}^{3+}$, and $\mathrm{Er}^{3+}$ ions, as well as the proposed upconversion mechanisms to produce the visible luminescent bands with Stark splitting in $\mathrm{NaYF}_{4}$ host materials. Figure S6: plot of upconversion luminescence intensities as a function of exposure time. Figure S7: schematic illustration of surface oxidation and bioconjugation of nanoprobes. After two hydrophobic samples are converted to be hydrophilic, CD20 and CD5 antibodies are conjugated with them via EDC/NHS agents to become CD20 and CD5 nanoprobes in order to identify mantle cell lymphoma from B-cell lymphoma. Figure S8: FT-IR spectra of samples before and after oxidization. Figure S9: $\mathrm{MnO}_{2}$ precipitation (a) and non- $\mathrm{MnO}_{2}$ precipitation (b). Figure S10: upconversion luminescence spectra of the oxidized samples under a $980 \mathrm{~nm}$ laser excitation. Figure S11: bright field (a, d), blue (b), and green (e) upconversion fluorescence images, as well as single overlays (c and $f$ ). $(10 \times, 1 \mathrm{bar}=50 \mu \mathrm{m})$, in where quadrangles of short dash dot are the expanded beam spot of laser. Figure S12: bright field and blue/green upconversion fluorescence images of Jeko- 1 cells, as well as their overlays $(20 \times, 1$ bar $=20 \mu \mathrm{m})$. Figure S13: bright field and blue/green upconversion fluorescence images of Jeko- 1 cells, as well as their overlays (40x, $1 \mathrm{bar}=10 \mu \mathrm{m})$. Figure S14: bright field and blue/green upconversion fluorescence images of Jeko-1 cells, as well as their overlays $(40 \times, 1 \mathrm{bar}=10 \mu \mathrm{m})$. Figure S15: bright field and blue/green upconversion fluorescence images of Jeko- 1 cells, as well as their overlays $(40 \times, 1 \mathrm{bar}=10 \mu \mathrm{m})$. Figure S16: bright field and blue/green upconversion fluorescence images of Jeko-1 cells, as well as their overlays $(40 \times, 1 \mathrm{bar}=10 \mu \mathrm{m})$. Figure S17: bright field and blue/ green upconversion fluorescence images of Jeko-1 cells, as well as their overlays $(40 \times, 1 \mathrm{bar}=10 \mu \mathrm{m})$. Figure S18: bright field and blue/green upconversion fluorescence images of Jeko- 1 cells, as well as their overlays (40×, 1 bar $=10 \mu \mathrm{m}$ ). Figure S19: bright field and blue singlelabeling upconversion fluorescence images of Raji cells, as well as the overlay $(40 \times, 1 \mathrm{bar}=10 \mu \mathrm{m})$. Supplemental data III: the proposed upconversion mechanisms. Supplemental data IV: a simple explanation on the improved upconversion. (Supplementary Materials)

\section{References}

[1] K. Tazawa and Y. Tsutsumi, "Effect of prolonged staining with hematoxylin on detecting Helicobacter pyiori in hematoxylin-eosin-stained gastric mucosa," Pathology International, vol. 48, no. 6, pp. 448-452, 1998.

[2] L. Zhang, H. Kong, C. T. Chin et al., "Automation-assisted cervical cancer screening in manual liquid-based cytology with hematoxylin and eosin staining," Cytometry Part A, vol. 85, no. 3, pp. 214-230, 2014.

[3] X.-L. Shi, G.-J. Mao, X.-B. Zhang et al., "Rhodamine-based fluorescent probe for direct bio-imaging of lysosomal $\mathrm{pH}$ changes," Talanta, vol. 130, pp. 356-362, 2014.

[4] T. Takashi, O. Satoru, K. Kengo, O. Masahiro, and S. Hideo, "Preclinical evaluation of a novel cyanine dye for tumor imaging with in vivo photoacoustic imaging," Journal of Biomedical Optics, vol. 19, no. 9, article 090501, 2014.

[5] G. S. Yi and G. M. Chow, "Synthesis of hexagonal-phase $\mathrm{NaYF}_{4}: \mathrm{Yb}, \mathrm{Er}$ and $\mathrm{NaYF}_{4}: \mathrm{Yb}, \mathrm{Tm}$ nanocrystals with efficient up-conversion fluorescence," Advanced Functional Materials, vol. 16, no. 18, pp. 2324-2329, 2006.

[6] O. Ehlert, R. Thomann, M. Darbandi, and T. Nann, "A fourcolor colloidal multiplexing nanoparticle system," ACS Nano, vol. 2, no. 1, pp. 120-124, 2008.

[7] D. Yang, Q. Chen, W. Wang, and S. Xu, "Direct and indirect immunolabelling of HeLa cells with quantum dots," Luminescence, vol. 23, no. 3, pp. 169-174, 2008.

[8] M. Bruchez Jr, M. Moronne, P. Pin, S. Weiss, and A. P. Alivisatos, "Semiconductor nanocrystals as fluorescent biological labels,” Science, vol. 281, no. 5385, pp. 2013-2016, 1998.

[9] D. Gerion, F. Chen, B. Kannan et al., "Room-temperature single-nucleotide polymorphism and multiallele DNA detection using fluorescent nanocrystals and microarrays," Analytical Chemistry, vol. 75, no. 18, pp. 4766-4772, 2003.

[10] X. Wu, H. Liu, J. Liu et al., "Immunofluorescent labeling of cancer marker Her2 and other cellular targets with semiconductor quantum dots," Nature Biotechnology, vol. 21, no. 1, pp. 41-46, 2003.

[11] F. Auzel, "Upconversion and anti-stokes processes with $\mathrm{f}$ and $\mathrm{d}$ ions in solids," Chemical Reviews, vol. 104, no. 1, pp. 139-174, 2004. 
[12] Q. Lü, F. Guo, L. Sun, A. Li, and L. Zhao, "Surface modification of $\mathrm{ZrO}_{2}: \mathrm{Er}^{3+}$ nanoparticles to attenuate aggregation and enhance upconversion fluorescence," The Journal of Physical Chemistry C, vol. 112, no. 8, pp. 2836-2844, 2008.

[13] F. Wang and X. Liu, "Recent advances in the chemistry of lanthanide-doped upconversion nanocrystals," Chemical Society Reviews, vol. 38, no. 4, pp. 976-989, 2009.

[14] M. Nyk, R. Kumar, T. Y. Ohulchanskyy, E. J. Bergey, and P. N. Prasad, "High contrast in vitro and in vivo photoluminescence bioimaging using near infrared to near infrared upconversion in $\mathrm{Tm}^{3+}$ and $\mathrm{Yb}^{3+}$ doped fluoride nanophosphors," Nano Letters, vol. 8, no. 11, pp. 3834-3838, 2008.

[15] G. Chen, T. Y. Ohulchanskyy, S. Liu et al., "Core/shell $\mathrm{NaGdF}_{4}: \mathrm{Nd}^{3+} / \mathrm{NaGdF}_{4}$ nanocrystals with efficient nearinfrared to near-infrared downconversion photoluminescence for bioimaging applications," ACS Nano, vol. 6, no. 4, pp. 2969-2977, 2012.

[16] J. L. West and N. J. Halas, "Engineered nanomaterials for biophotonics applications: improving sensing, imaging, and therapeutics," Annual Review of Biomedical Engineering, vol. 5, no. 1, pp. 285-292, 2003.

[17] Q. Liu, Y. Sun, T. Yang, W. Feng, C. Li, and F. Li, "Sub-10 nm hexagonal lanthanide-doped $\mathrm{NaLuF}_{4}$ upconversion nanocrystals for sensitive bioimaging in vivo," Journal of the American Chemical Society, vol. 133, no. 43, pp. 17122-17125, 2011.

[18] X. Wang and Y. Li, "Monodisperse nanocrystals: general synthesis, assembly, and their applications," Chemical Communications, vol. 28, pp. 2901-2910, 2007.

[19] D. Chatterjee, A. Rufaihah, and Y. Zhang, "Upconversion fluorescence imaging of cells and small animals using lanthanide doped nanocrystals," Biomaterials, vol. 29, no. 7, pp. 937-943, 2008.

[20] S. Jiang, Y. Zhang, K. M. Lim, E. K. W. Sim, and L. Ye, "NIRto-visible upconversion nanoparticles for fluorescent labeling and targeted delivery of siRNA," Nanotechnology, vol. 20, no. 15, article 155101, 2009.

[21] H. Guo, N. M. Idris, and Y. Zhang, "LRET-based biodetection of DNA release in live cells using surface-modified upconverting fluorescent nanoparticles," Langmuir, vol. 27, no. 6, pp. 2854-2860, 2011.

[22] M. Wang, C. C. Mi, W. X. Wang et al., "Immunolabeling and NIR-excited fluorescent imaging of HeLa cells by using NaY$\mathrm{F}_{4}: \mathrm{Yb}$,Er upconversion nanoparticles," ACS Nano, vol. 3, no. 6, pp. 1580-1586, 2009.

[23] M. Wang, C. Mi, Y. Zhang et al., "NIR-responsive silica-coated $\mathrm{NaYbF}_{4}: \mathrm{Er} / \mathrm{Tm} / \mathrm{Ho}$ upconversion fluorescent nanoparticles with tunable emission colors and their applications in immunolabeling and fluorescent imaging of cancer cells," The Journal of Physical Chemistry C, vol. 113, no. 44, pp. 19021-19027, 2009.

[24] Y. Sun, X. Zhu, J. Peng, and F. Li, "Core-shell lanthanide upconversion nanophosphors as four-modal probes for tumor angiogenesis imaging," ACS Nano, vol. 7, no. 12, pp. 1129011300, 2013.

[25] X. Zhu, B. da Silva, X. Zou et al., "Intra-arterial infusion of PEGylated upconversion nanophosphors to improve the initial uptake by tumors in vivo," RSC Advances, vol. 4, no. 45, pp. 23580-23584, 2014.

[26] X. F. Qiao, J. C. Zhou, J. W. Xiao, Y. F. Wang, L. D. Sun, and C. H. Yan, "Triple-functional core-shell structured upconversion luminescent nanoparticles covalently grafted with photosensitizer for luminescent, magnetic resonance imaging and photodynamic therapy in vitro," Nanoscale, vol. 4, no. 15, pp. 4611-4623, 2012.

[27] Y.-F. Wang, G.-Y. Liu, L.-D. Sun, J.-W. Xiao, J.-C. Zhou, and C. H. Yan, " $\mathrm{Nd}^{3+}$-sensitized upconversion nanophosphors: efficient in vivo bioimaging probes with minimized heating effect," ACS Nano, vol. 7, no. 8, pp. 7200-7206, 2013.

[28] J. Shen, G. Chen, T. Y. Ohulchanskyy et al., "Tunable near infrared to ultraviolet upconversion luminescence enhancement in $\left(\alpha-\mathrm{NaYF}_{4}: \mathrm{Yb}, \mathrm{Tm}\right) / \mathrm{CaF}_{2}$ core/shell nanoparticles for in situ real-time recorded biocompatible photoactivation," Small, vol. 9, no. 19, pp. 3213-3217, 2013.

[29] S. Liu, G. Chen, T. Y. Ohulchanskyy, M. T. Swihart, and P. N. Prasad, "Facile synthesis and potential bioimaging applications of hybrid upconverting and plasmonic $\mathrm{NaGdF}_{4}: \mathrm{Yb}^{3+}, \mathrm{Er}^{3+} /$ silica/gold nanoparticles," Theranostics, vol. 3, no. 4, pp. 275-281, 2013.

[30] Y. Dai, P. Ma, Z. Cheng et al., "Up-conversion cell imaging and $\mathrm{pH}$-induced thermally controlled drug release from $\mathrm{NaYF}_{4}: \mathrm{Yb}^{3+} / \mathrm{Er}^{3+} @$ hydrogel core-shell hybrid microspheres," ACS Nano, vol. 6, no. 4, pp. 3327-3338, 2012.

[31] Y. Dai, H. Xiao, J. Liu et al., "In vivo multimodality imaging and cancer therapy by near-infrared light-triggered transplatinum pro-drug-conjugated upconverison nanoparticles," Journal of the American Chemical Society, vol. 135, no. 50, pp. 18920-18929, 2013.

[32] Y. Yang, Q. Shao, R. Deng et al., "In vitro and in vivo uncaging and bioluminescence imaging by using photocaged upconversion nanoparticles," Angewandte Chemie International Edition, vol. 51, no. 13, pp. 3125-3129, 2012.

[33] Q. Chen, C. Wang, L. Cheng, W. He, Z. Cheng, and Z. Liu, "Protein modified upconversion nanoparticles for imagingguided combined photothermal and photodynamic therapy," Biomaterials, vol. 35, no. 9, pp. 2915-2923, 2014.

[34] S. Hu, X. Wu, Z. Tang et al., "Upconversion $\mathrm{NaYF}_{4}$ nanoparticles for size dependent cell imaging and concentration dependent detection of Rhodamine B," Journal of Nanomaterials, vol. 2015, Article ID 598734, 10 pages, 2015.

[35] Z. Chen, X. Wu, S. Hu et al., "Multicolor upconversion $\mathrm{NaLuF}_{4}$ fluorescent nanoprobe for plant cell imaging and detection of sodium fluorescein," Journal of Materials Chemistry C, vol. 3, no. 1, pp. 153-161, 2015.

[36] Z. Chen, X. Wu, S. Hu et al., "Upconversion $\mathrm{NaLuF}_{4}$ fluorescent nanoprobes for jellyfish cell imaging and irritation assessment of organic dyes," Journal of Materials Chemistry C, vol. 3, no. 23, pp. 6067-6076, 2015.

[37] M. Wang, Y. Zhu, and C. Mao, "Synthesis of NIR-responsive $\mathrm{NaYF}_{4}: \mathrm{Yb}$,Er upconversion fluorescent nanoparticles using an optimized solvothermal method and their applications in enhanced development of latent fingerprints on various smooth substrates," Langmuir, vol. 31, no. 25, pp. 70847090, 2015.

[38] M. Wang, "Latent fingermarks light up: facile development of latent fingermarks using NIR-responsive upconversion fluorescent nanocrystals," RSC Advances, vol. 6, no. 43, pp. 36264-36268, 2016.

[39] P. Pérez-Galán, M. Dreyling, and A. Wiestner, "Mantle cell lymphoma: biology, pathogenesis and the molecular basis of treatment in the genomic era," Blood, vol. 117, no. 1, pp. 26-38, 2011. 
[40] B. Y. Chang, M. Francesco, M. F. M. de Rooij et al., "Egress of $\mathrm{CD} 19^{+} \mathrm{CD}^{+}$cells into peripheral blood following treatment with the Bruton tyrosine kinase inhibitor ibrutinib in mantle cell lymphoma patients," Blood, vol. 122, no. 14, pp. 24122424, 2013.

[41] H. J. Jeon, C. W. Kim, T. Yoshino, and T. Akagi, "Establishment and characterization of a mantle cell lymphoma cell line," British Journal of Haematology, vol. 102, no. 5, pp. 1323-1326, 1998.

[42] H. M. Amin, T. J. McDonnell, L. J. Medeiros et al., "Characterization of 4 mantle cell lymphoma cell lines," Journal Archives of Pathology \& Laboratory Medicine, vol. 127, no. 4, pp. 424431, 2003.

[43] M. Kikuchi and M. Shigeo, New Atlas of Malignant Lymphoma, Bunkodo Co. Ltd., Tokyo, Japan, 2004.

[44] R. Griffiths, J. Mikhael, M. Gleeson, M. Danese, and M. Dreyling, "Addition of rituximab to chemotherapy alone as first-line therapy improves overall survival in elderly patients with mantle cell lymphoma," Blood, vol. 118, no. 18, pp. 4808-4816, 2011.

[45] M. J. Rummel, N. Niederle, G. Maschmeyer et al., "Bendamustine plus rituximab versus $\mathrm{CHOP}$ plus rituximab as first-line treatment for patients with indolent and mantlecell lymphomas: an open-label, multicentre, randomised, phase 3 non-inferiority trial," Lancet, vol. 381, no. 9873, pp. 1203-1210, 2013.

[46] A. Montraveta, S. Xargay-Torrent, M. López-Guerra et al., "Synergistic anti-tumor activity of acadesine (AICAR) in combination with the anti-CD20 monoclonal antibody rituximab in in vivo and in vitro models of mantle cell lymphoma," Oncotarget, vol. 5, no. 3, pp. 726-739, 2014.

[47] R. U. Lemieux and E. Von Rudloff, "Periodate-permanganate oxidations: I. Oxidation of olefins," Canadian Journal of Chemistry, vol. 33, no. 11, pp. 1701-1709, 1955.

[48] Z. Chen, H. Chen, H. Hu et al., "Versatile synthesis strategy for carboxylic acid-functionalized upconverting nanophosphors as biological labels," Journal of the American Chemical Society, vol. 130, no. 10, pp. 3023-3029, 2008.

[49] X. Wang, J. Zhuang, Q. Peng, and Y. Li, “A general strategy for nanocrystal synthesis," Nature, vol. 437, no. 7055, pp. 121124, 2005.

[50] Z. Zhuang, Q. Peng, J. Liu, X. Wang, and Y. Li, "Indium hydroxides, oxyhydroxides, and oxides nanocrystals series," Inorganic Chemistry, vol. 46, no. 13, pp. 5179-5187, 2007.

[51] R. Balda, A. J. Garcia-Adeva, M. Voda, and J. Fernández, "Upconversion processes in $\mathrm{Er}^{3+}$-doped $\mathrm{KPb}_{2} \mathrm{Cl}_{5}$," Physical Review B, vol. 69, no. 20, article 205203, 2004.

[52] Q. Lü, A. H. Li, F. Y. Guo, L. Sun, and L. C. Zhao, "Experimental study on the surface modification of $\mathrm{Y}_{2} \mathrm{O}_{3}: \mathrm{Tm}^{3+} / \mathrm{Yb}^{3+}$ nanoparticles to enhance upconversion fluorescence and weaken aggregation," Nanotechnology, vol. 19, no. 14, pp. 145701-145709, 2008.

[53] Q. Lü, A. H. Li, F. Y. Guo, L. Sun, and L. C. Zhao, “The twophoton excitation of $\mathrm{SiO}_{2}$-coated $\mathrm{Y}_{2} \mathrm{O}_{3}: \mathrm{Eu}^{3+}$ nanoparticles by a near-infrared femtosecond laser," Nanotechnology, vol. 19, no. 20, pp. 205704-205708, 2008.

[54] Q. Lü, F. Y. Guo, L. Sun, A. H. Li, and L. C. Zhao, "Silica-/ titania-coated $\mathrm{Y}_{2} \mathrm{O}_{3}: \mathrm{Tm}^{3+}, \mathrm{Yb}^{3+}$ nanoparticles with improvement in upconversion luminescence induced by different thickness shells," Journal of Applied Physics, vol. 103, no. 12, pp. 123533-123510, 2008.
[55] "Instruction book on Pierce ${ }^{\mathrm{TM}}$ EDC Crosslinker and Pierce ${ }^{\mathrm{TM}}$ NHS Crosslinker (Thermo Scientific)," http://www.piercenet. com/product/edc and http://www.piercenet.com/product/ nhs-sulfo-nhs.

[56] N. J. Mol and M. J. E. Fischer, Surface Plasmon Resonance: Methods and Protocols, Humana Press (CSpringer Science + Business Media, LLC, New York, NY, USA, 2010.

[57] B. Das, M. O. Mondragon, S. Z. Tao, and A. J. Norin, "Preferential interaction of a novel tumor surface protein (p38.5) with naive natural killer cells," Journal of Experimental Medicine, vol. 185, no. 10, pp. 1735-1742, 1997.

[58] G. A. M. Smith, H.-W. Tsui, E. W. Newell et al., "Functional up-regulation of HERG $\mathrm{K}^{+}$channels in neoplastic hematopoietic cells," Journal of Biological Chemistry, vol. 277, no. 21, pp. 18528-18534, 2002.

[59] L. Fan, D. Lou, Y. Zhang, and N. Gu, "Rituximab-Au nanoprobes for simultaneous dark-field imaging and DAB staining of CD20 over-expressed on Raji cells," Analyst, vol. 139, no. 22 , pp. 5660-5663, 2014. 


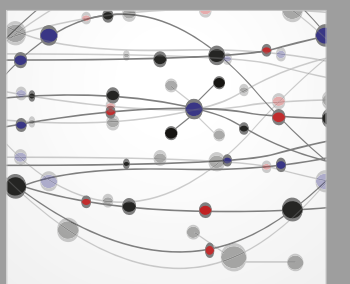

The Scientific World Journal
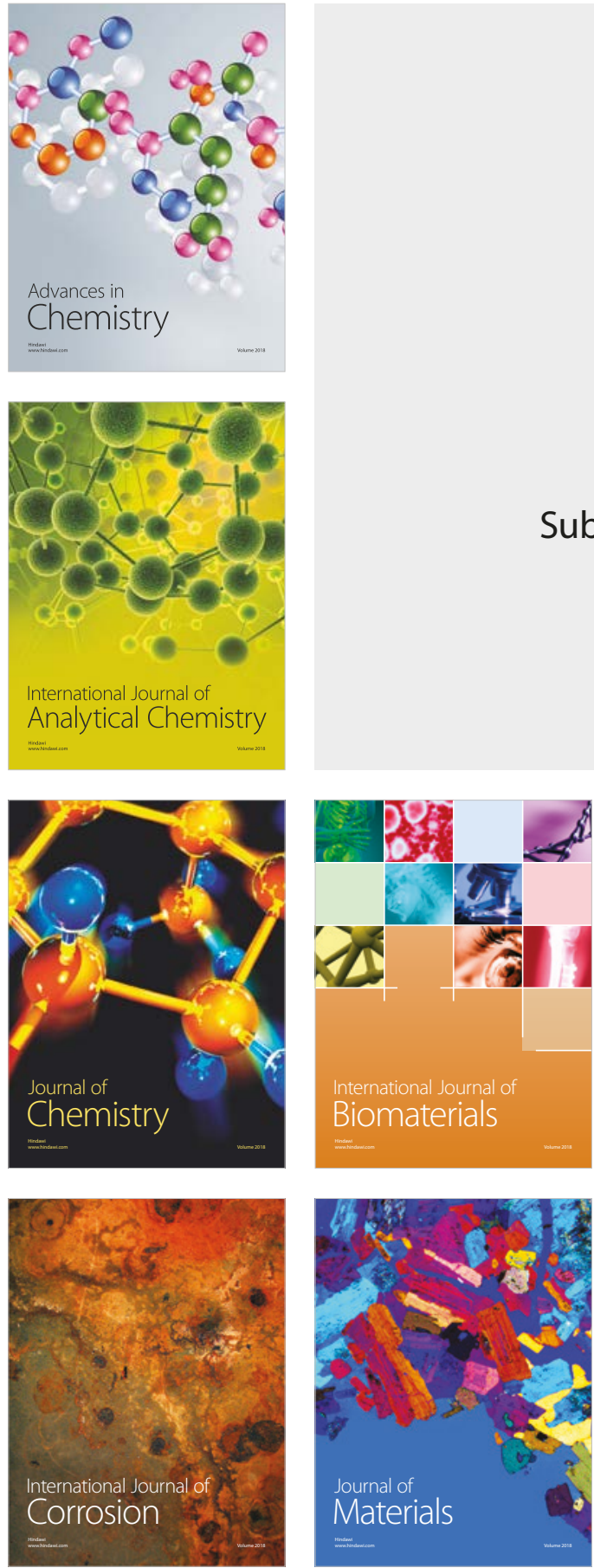

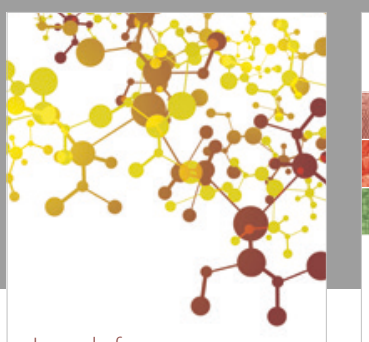

Journal of

Applied Chemistry
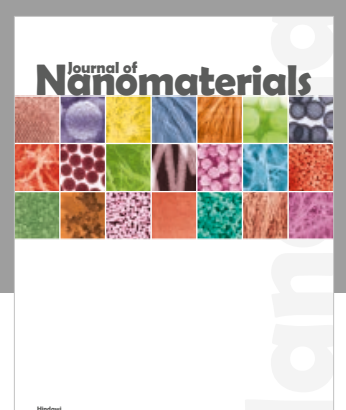

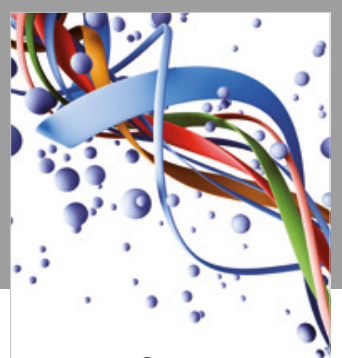

Scientifica

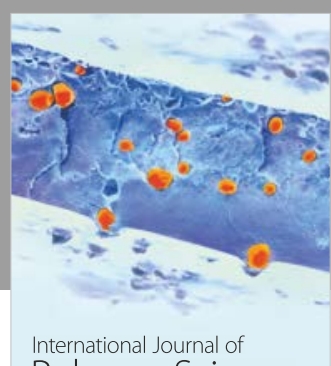

Polymer Science

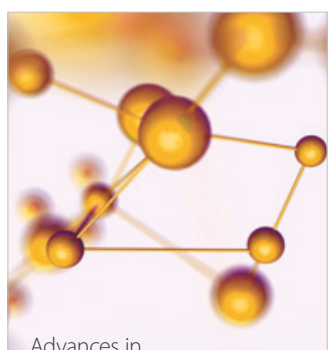

Physical Chemistry
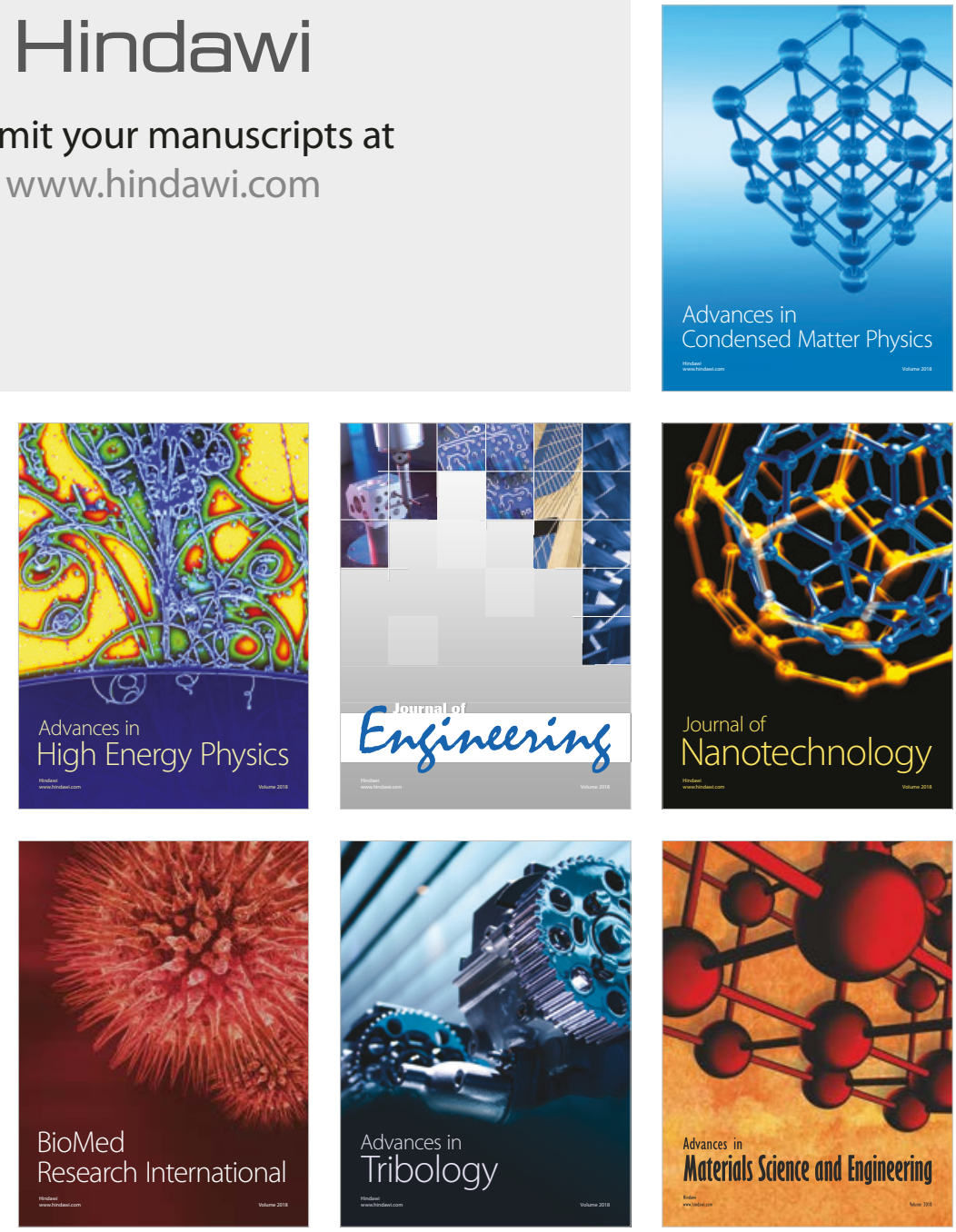